\title{
Capitales golondrina, estabilidad y desarrollo ${ }^{1}$
}

\author{
Ricardo Ffrench-Davis
}

El financiamiento externo ha jugado un papel muy importante en América Latina, especialmente en los últimos veinte años. Por ello se hace necesaria una evaluación acerca de sus características, de los problemas y posibilidades que plantea, y de sus implicancias sobre las políticas económicas. El presente artículo pretende avanzar en esa dirección. Primero se discuten algunos de los rasgos principales de este financiamiento externo en los afios noventa en la región, en comparación con lo ocurrido durante las décadas del setenta y del ochenta, enfatizando ciertas características típicas de este tipo de financiamiento. Enseguida se examinan algunos aspectos de la crisis mexicana de diciembre de 1994 -el llamado "efecto tequila"- sus consecuencias en Argentina y su contraste con lo ocurrido en Chile, lo cual se explica principalmente porque este país siguió un camino muy distinto al de México y Argentina: el de la regulacióny control de los movimientos de capital y una política cambiaria más activa, para atenuar la inestabilidad y vulnerabilidad de la economía interna, asociadas a las fluctuaciones de estos flujos.

\section{Financiamiento externo en los dos últimos decenios.}

Como se sabe, los flujos de capital tienen un impacto significativo sobre la economía real, afectando el nivel de empleo, los salarios, el proceso de formación de capital, etc. Este impacto depende de las condiciones

\footnotetext{
${ }^{1}$ Transcripción de la conferencia pronunciada en el Seminario Internacional "Los nuevos desafios en la economia latinoamericana", ILDIS, Quito, 26-27 de marzo de 1996. Las opiniones emitidas aqui sólo comprometen a su autor.
} 
concretas del mercado internacional de capitales y de la manera cómo los paises receptores las enfrentan.

A partir de los años setenta los mercados financieros internacionales experimentaron un cambio sustancial. El mercado financiero habia sido impactado dramáticamente durante la crisis de los años 30 . En efecto, mientras en la década del veinte hubo abundancia de financiamiento externo, la crisis de la década siguiente crea un corte del financiamiento privado que dura casi cuatro décadas. Frente a esta situación, finalizada la Segunda Guerra Mundial, las autoridades mundiales responden creando instituciones multilaterales públicas que brindan financiamiento, tanto de corto plazo (el Fondo Monetario Intemacional) como de largo plazo (el Banco Mundial). El financiamiento privado no resurge, sino hasta los años setenta.

En este nuevo período de gran abundancia, casi todos los países de América Latina recibieron préstamos de la banca comercial privada, que era la principal fuente de financiamiento de aquella época. Luego, en los años ochenta, nuevamente hay escasez de créditos y los antiguos aún vigentes quedaron afectos a tasas de interés notablemente altas, independientemente de los "méritos" que hicieran los paises. Esto configuró la llamada crisis de la deuda externa.

Este comportamiento ilustra una característica muy importante del financiamiento externo: su naturaleza fluctuante. Así, se producen periodos de abundancia de capital, en las que todos pueden acceder con muy poca condicionalidad y de manera bastante expedita al financiamiento externo, seguidos de períodos de gran escasez de fondos. En los años ochenta, un factor dominante de la recesión que invadió a toda América Latina es la crisis de la deuda que le costó a la región alrededor de US\$ 40 mil millones por año en promedio en subutilización de la capacidad productiva. Esto se tradujo en una cantidad enorme de trabajo y capital perdida o subutilizada, ya que si se trataba de elevar la utilización de la capacidad a través de aumentos de la demanda interna, parte de esa mayor demanda se destinaría a importaciones en un contexto de aguda escasez de divisas, dada la reducción del financiamiento externo y porque gran parte de los dólares se destinaba a pagar los intereses o a amortizar la deuda acumulada en los años setenta.

De esta manera, en los años ochenta se consolida una situación recesiva, al margen de las políticas y orientaciones de los paises. Esto se debió al corte del financiamiento externo, es decir, a un cambio exógeno, originado en el mercado financiero internacional. 
En los años noventa, empieza a recuperarse el financiamiento externo, dẻbido a la reducción de las tasas de interés internacionales, asociada a la política monetaria de los Estados Unidos. Ante esto, las instituciones financieras y las empresas cómienzan a buscar mercados extemos alternàtivos para invertir sưs recursos. Esto redunda en el resurgimiento de abundantes y diversificadas fuentes de financiamiento para diversos países en desarrollo, que no sólo reciben ofertas de créditos, sino que América Latina se encuentra con otros distintos canales, como depósitos, bonos, compras de acciones e inversión extranjera directa.

En definitiva, hay un cambio radical en las condiciones del mercado internacional de capitales, el cual es en una medida significativa de naturaleza exógena, es decir, independiente de las políticas económicas $y$ reformas de los paises de la región. En esto hay una asimetría, dado que si bien no podemos transformar la escasẹz en abundancia, sí podemos, en épocas de disponibilidad de recursos externos, condicionar las formas de financiamiento, su monto y composición a las conveniencias de nuestras economías. En los años setenta y en los noventa América Latina podía escoger.

Cuando hay muchos recursos disponibles hay también muchos agentes y promotores trayéndolos y ofreciéndolos en nuestros paises. Del mismo modo, hay diversas formas en que estos capitales pueden ingresar a la región (bonos, depósitos bancarios, créditos, inversión extranjera directa que venga ya sea a comprar lo existente o a crear nuevas empresas). En consecuencia, tenemos un espacio para seleccionar cuáles de estas formas son las más convenientes.

También podemos escoger el uso que le damos a estos fondos. podemos dirigirlos a fortalecer el proceso de formación de capital (inversión), de modo que haya más empleos productivos en el futuro y la economía genere capacidad de pago respecto de los que colocan sus recursos en la región; o se pueden destinar al consumo, con lo cual no se genera capacidad de pago y simplemente nos quedamos con el pasivo que hay que servir en el futuro. Estos son aspectos en los que los países de la región podemos incidir a través de las políticas económicas, más allá de las recetas que recibimos, ya que se puede escoger los ingredientes específicos adicionales a la receta genérica. 


\section{Espacio para una política nacional.}

Daremos dos ejemplos que ilustran el hecho de que podemos condicionar los montos, modalidades y usos que se da a los recursos provenientes del exterior. En los años setenta, Colombia optó por endeudarse poco $y$, además, canalizó esos fondos hacia la inversión. De este modo, fue el país menos afectado por la crisis de la deuda. Algunos piensan que fue gracias al dinero proveniente del narcotráfico pero, yo diría que todo lo contrario, pese a él, ya que el narcotráfico complica mucho el manejo público, atentando contra la honestidad y la estabilidad macroeconómica.

El segundo ejemplo tiene que ver con los distintos caminos escogidos por los países en los años noventa. Particularmente destaca Chile, que optó por percibir menos financiamiento externo, dando preferencia a capitales de más largo plazo, menos especulativos y más asociados al desarrollo productivo. ${ }^{2}$ Esto se hace aplicando regulaciones y restricciones a los ingresos de capital: impuestos y reservas o encajes sobre los créditos y depósitos extemos, y ciertas compras bursátiles. Otro país que emplea algunas políticas parciales es Brasil, que está aplicando mecanismos de regulación y desaliento a los ingresos de capital especulativo.

Algunos observadores piensan que no hay necesidad de regulación alguna, porque si el dinero es mal utilizado en un país los propios inversionistas sabrian detenerse a tiempo y cesarian de colocar recursos alli. En teoría, para quienes creen excesivamente en el funcionamiento de los mercados, éstos se detendrían antes de llegar al precipicio.

Sin embargo, esto no sucede en la práctica, ya que en los movimientos de capital hay inversionistas que tienen un horizonte de diez o veinte años plazo y están evaluando las distintas variables en juego, mientras hay otros que más bien están mirando a la mañana siguiente, es decir, calculando las ganancias por días o semanas. Los agentes de esta segunda categoría no se interesan mayormente ni en las variables macroeconómicas, ni en el grado de endeudamiento del país, ni en el atraso del tipo de cambio o la inversión global. Ellos se guían únicamente por lo que pasa con la tasa de interés que reciben, o por los precios de las acciones o de los bonos que tienen comprometidos en ese mercado, y están atentos a que el atraso cambiario o déficit externo se pueda sostener un poco más tiempo.

\footnotetext{
${ }^{2}$ Un examen detallado de la experiencia de Chile se desarrolla en Ffrench-Davis, Agosin y Uthoff, "Movimientos de capitales, estrategia exportadora y estabilidad macroeconómica en Chile", en Ffrench-Davis y Griffith-Jones (eds.), Las nuevas corrientes financieras hacia la América Latina, (Santiago y México: Fondo de Cultura Económica, 1995).
} 
Este inversionista cortoplacista suele tener un horizonte de tiempo muy limitado y perder la perspectiva sobre lo que está pasando en la tendencia de los mercados. Esto explica por qué muchos inversionistas todavía invertian, por ejemplo, el 10 de diciembre de 1994 en México para días después, el 20 del mismo mes, cuando ocurrió la debacle, señalen que el país estaba haciendo mal las cosas. Sólo dos semanas antes estaban alabando estentoriamente su manejo económico: Esto sucede cuando se está mirando a muy corto plazo y no se tiene presente lo que se dijo dos o tres semanas antes. Por lo general, la decisión siguiente es irse y no volver a ese mercado por un buen tiempo.

Entonces, la política económica debe buscar privilegiar aquellos flujos de capital que tengan horizontes de más largo plazo y los volúmenes de capital que sean más consistentes con nuestra capacidad de absorción eficiente y con la sustentabilidad macroeconómica.

Es necesario, primero, examinar el rol del financiamiento externo. ${ }^{3}$ En particular, es relevante asegurar que los recursos externos sirvan como complemento al ahorro y la inversión internos. Esto es decisivo porque todos los países de América Latina, sin excepción, invierten y ahorran poco. Además, la inversión es clave para el crecimiento económico, es decir, para aumentar la disponibilidad de bienes y servicios en nuestras economias, y para generar empleos productivos en número sustancialmente superior al magro resultado de los años recientes. Para ello es imprescindible aumentar la formación de capital, crear nuevas fábricas, mejorar la infraestructura, reformar la educación y fortalecer la capacitación laboral, expandir las vias de transporte para que los bienes y servicios fluyan más expeditamente desde la producción hacia el consumo. En estos aspectos tenemos serias carencias en la región. Necesitamos mayor y mejor inversión, lo cual determina la capacidad de crecer, y el país que crece tiene mayores posibilidades de reducir la pobreza.

Si aplicamos políticas de crecimiento con equidad, se combina el crecimiento económico con la reducción de la desigualdad en nuestros países. Esto es esencial, ya que hay 200 millones de personas que estaban bajo la línea de pobreza hacia comienzos de la presente década.

Los fondos provenientes del exterior constituyen una parte de la producción del resto del mundo que no se consumió ni invirtió en esos paises. Es un ahorro excedente que puede llegar a nuestros países a complementar el ahorro nacional y, de ese modo, sumarse para elevar la

${ }^{3}$ Esto es tratado en Ffrench-Davis y Griffith-Jones, op. cit., donde se examinan varios de estos objetivos, los origenes de los recursos que llegan a América Latina y sus caracteristicas y luego se revisa la experiencia reciente de Argentina, Chile y México. 
inversión interna y generar más empleo productivo con mejores ingresos en el tiempo.

Entonces, desde un punto de vista simplista, se podría creer que todo capital debe ser bienvenido porque así se puede crecer más. El problema es que cuando los fondos son excesivos no se les puede canalizar hacia la inversión y se destinan excesivamente al consumo. Este consumo no se puede sustentar en el tiempo, porque el mundo no transfiere recursos de manera gratuita e indefinida. En consecuencia, es necesario tener una capacidad de absorción eficiente de estos fondos, para que se dirijan fundamentalmente hacia el proceso de formación de capital.

Adicionalmente, los inversionistas extranjeros obviamente quieren recibir sus intereses o utilidades no en monedas locales sino en divisas "fuertes", lo que exige que la inversión deba ser dirigida en una parte significativa a los sectores productores de bienes y servicios transables (comercializables internacionalmente). Esto quiere decir que es imprescindible producir divisas vía exportaciones y/o reducir los gastos en dólares vía sustitución de importaciones. Sin embargo, muchas veces sucede que, cuando hay abundancia de fondos externos en el mercado, no se aplican políticas adecuadas. En este sentido, el mercado es miope y reacciona abaratando lo que aparece abundante en el corto plazo y entonces el tipo de cambio se aprecia. Es decir, el dólar baja de precio en relación a la moneda local, reduciéndose así los incentivos para producir bienes exportables y sustitutos de importaciones.

En consecuencia, esa estrategia tiende a autoderrotarse, ya que los recursos se canalizan hacia el consumo de productos importados. Para que la estrategia sea sustentable, tiene que haber una proporción sustancial destinada a la inversión y, de ella, una parte significativa comprometida en la producción de exportables o sustitutos de importaciones.

Sin embargo, los agentes tienden a guiarse espontáneamente por las señales que da el mercado de corto plazo (tipo de cambio y tasas de interés, especialmente). Así, cuando la tasa de interés interna se mantiene alta, las empresas tienen más incentivos para colocar sus recursos en forma de depósitos financieros antes que en inversión productiva. Adicionalmente, cuando hay exceso de financiamiento externo, tiende a desarrollarse mucho el crédito intemo al consumo, y para adquirir acciones o bienes raices existentes, lo que no aporta a la capacidad productiva nacional. Por el contrario, los precios de las acciones empiezan a subir, así como el precio de la propiedad. En economia, a este proceso de elevación de precios de activos sin una base de sustentación en la producción real se le llama "burbujas". 
Lá única base de sustentación real es la productividad, con una inversión más elevada, mayores niveles de empleo, creciente capacitación laboral, etc. Cuando esas "burbujas" de repente explotan, nos damos cuenta que dentro de ella había esencialmente elementos especulativos y no capacidad productiva en expansión.

El resultado final depende de las políticas que se apliquen internamente y de las condiciones del mercado internacional de capitales. Este último aspecto tiene que ver con el fenómeno de la globalización que es intenso pero no es parejo ni homogéneo. Algunos componentes de la globalización han evolucionado en el mundo de una manera mucho más veloz y, en particular, lo financiero de corto plazo. Si bien es cierto que ha habido inversión extranjera que viene a crear nuevas capacidades productivas o préstamos para la compra de equipos y maquinaria, lo que ha crecido notoriamente es el financiamiento a corto plazo, asociado a actividades especulativas. Por ejemplo, los recursos que pasan fronteras para comprar acciones o que llegan para depositarse en los bancos locales para aprovechar tasas de interés más elevadas que las tasas vigentes en otros mercados.

De hecho, en el mundo la inversión extranjera directa es una fracción minoritaria de los fondos que cruzan fronteras. En términos netos, representan un $1 \%$ del PIB mundial. La cifra media en la región es de un orden similar. Frente a esta realidad, si no aplicamos políticas adecuadas, van a ingresar muchos capitaies de corto plazo, flujos especulativos antes que productivos $\mathrm{y}$, como no podremos absorber eficientemente esos recursos, se va a crear una economia llena de "burbujas", con precios que crecen aceleradamente y que repentinamente se desploman. Más aún, cuando se desploman, los inversionistas se asustan y retiran masivamente sus recursos. Es lo que le sucedió a México y a Argentina en 1995 , y es lo que anteriormente le ocurrió a toda la región en 1981 y 1982 , con la crisis anterior que fue mucho más generalizada y profunda.

Esta realidad del mercado intemacional nos indica que tenemos que ser mucho más cautos y mucho más activos. Aquí hay una tarea macroeconómica central, que consiste en tener financiamiento extemo en montos susceptibles de ser absorbidos eficientemente por nuestras economías y que además vaya dirigido a sectores transables, de modo que permita mantener un circuito sostenible en el tiempo.

En el Cuadro 1 se puede observar la magnitud de los déficit en cuenta corriente registrados en diversos países y en la región en su conjunto. La excepción es Brasil, que representa alrededor de un tercio del producto total de la región, quien muestra una situación peculiar ya que por varios 
R. Ffrench-Davis / Capitales golondrina, estabilidad ...

años tuvo un superávit en la cuenta corriente; éste se tomó negativo y se elevó bruscamente en 1995 a 3\% de su PIB, para reducirse en 1996 gracias a las políticas adoptadas internamente.

\section{Cuadro 1}

América Ĺatina: déficit externo, inversión y tipos de cambio

\begin{tabular}{|c|c|c|c|c|c|c|}
\hline \multicolumn{5}{|c|}{$\begin{array}{l}\text { DEFICIT EN CUENTA CORRIEN'TE } \\
\text { (Millones de US\$ de cada año) }\end{array}$} & \multirow{2}{*}{$\frac{\cdots}{1994}$} & \multirow{2}{*}{1995} \\
\hline & $1983-90$ & 1991 & 1992 & 1993 & & \\
\hline Argentina & 1413 & 647 & 6546 & 7031 & 9311 & 2277 \\
\hline Brasil & 1554 & 1443 & $(6140)$ & 592 & 1689 & 17784 \\
\hline Chile & 1101 & 287 & 1065 & 2421 & 1045 & 270 \\
\hline Colombia & 668 & (2363) & (925) & 2130 & 3033 & 4055 \\
\hline México & 592 & 14995 & 24919 & 23496 & 29514 & 736 \\
\hline Peni & 932 & 1649 & 2143 & 2092 & 2605 & 4197 \\
\hline América Latina b) & 7956 & 18901 & 36915 & 45656 & 50730 & 33314 \\
\hline A.L. - Venezuela & 9653 & 20670 & 33168 & 43663 & 53180 & 34864 \\
\hline \multicolumn{7}{|c|}{$\begin{array}{l}\text { FORMACION BRUTA DE CAPITAL FIJO } \\
\text { (\% del PIB a precios de 1980) }\end{array}$} \\
\hline & $1983-90$ & 1991 & 1992 & 1993 & 1994 & 1995 \\
\hline Argentina & 16.5 & 15.4 & 18.6 & 19.9 & 22.0 & 19.4 \\
\hline Brasil & 16.5 & 14.2 & 13.2 & 13.7 & 14.6 & 15.7 \\
\hline Chile & 15.3 & 17.2 & 19.6 & 21.7 & 21.6 & 22.3 \\
\hline Colombia & 15.7 & 12.6 & 13.7 & 17.7 & 19.1 & 21.1 \\
\hline México & 17.1 & 19.6 & 21.1 & 20.7 & 21.7 & 16.3 \\
\hline Perú & 17.6 & 17.3 & 18.0 & 18.8 & 22.4 & $\therefore$ n.d \\
\hline América Latina b) & 16.8 & 16.3 & 17.4 & 18.0 & 18.6 & 17.5 \\
\hline
\end{tabular}




\begin{tabular}{|lrrrrrrrr|}
\hline \multicolumn{7}{c|}{ INDICES DE TIPO DE CAMBIO REAC a) } \\
\multicolumn{7}{c|}{$(\mathbf{1 9 8 7}-\mathbf{9 0} \mathbf{- 1 0 0 )}$} \\
\hline Argentina & $1983-86$ & $1987-90$ & 1991 & 1992 & 1993 & 1994 & 1995 \\
Brasil & 78.5 & 100.0 & 67.3 & 62.6 & 60.1 & 63.3 & 70.3 \\
Chile & 117.2 & 100.0 & 93.2 & 100.5 & 90.8 & 73.1 & 55.5 \\
Colombia & 68.8 & 100.0 & 100.1 & 96.6 & 97.9 & 97.8 & 93.6 \\
México & 65.1 & 100.0 & 112.1 & 99.3 & 96.6 & 83.0 & 83.1 \\
Perú & 96.0 & 100.0 & 81.3 & 74.8 & 71.2 & 73.1 & 108.0 \\
América Latina b) c) & 97.4 & 100.0 & 87.1 & 86.0 & 81.1 & 74.8 & 76.4 \\
Promedio simple & 85.8 & 100.0 & 96.4 & 95.0 & 93.7 & 92.1 & 94.7 \\
$\quad$ A.L. & 136.4 & 100.0 & 54.0 & 53.2 & 54.8 & 55.7 & 56.3 \\
\hline
\end{tabular}

a) Corresponde al promedio anual de los indices de tipo de cambio real (oficial principal) de la - moneda de cada pás respecto de las monedas de los principales socios comerciales, ponderado por la importancia relativa de las exportaciones hacia esos países. Las ponderaciones corresponden al promedio del periodo 1989-92. Los indices, construidos con indices de precios al consumidor, se obtuvieron de CEPAL, Estudio Económico de América Latina y el Caribe 1981 y posteriores actualizaciones de la CEPAL.

b) América Latina incluye 19 paises.

c) El tipo de cambio real promedio de América Latina fue calculado considerando la participación relativa del PIB de los diferentes países, excluyenuo a Panamá. Para 1995, además de Panamá excluye a Haití y Nicaragua.

En la década de los ochenta ingresaron a la región un promedio de US\$ 10 mil millones de capital por año. En el trienio 1992-94 alcanza a US\$ 62 mil millones promedio anual. Ciertamente estos recursos no llegan el mismo día a todos los países, sino que van ingresando progresivamente. Las entidades privadas instaladas en los países desarrollados no invierten en todos los países al mismo tiempo pero, hacia fines de 1994, estaban operando prácticamente en la mayoría de los países de la región.

Así, en los tres años anteriores a la crisis mexicana, como se señaló recién, habian ingresado alrededor de US\$62 mil millones netos por año. Sin embargo, sólo uno de cada cuatro dólares correspondía a inversión extranjera directa. La gran mayoria de los recursos están constituidos por bonos de 28 a 90 días plazo y depósitos bancarios de 30 o 60 días que circulaban por todos los países de la región. También es útil examinar cómo se usan estos recursos. Entre 1991 y 1993, los Bancos Centrales compraron muchos más dólares que lo que vendieron, de modo que acumularon reservas dado que había mucha oferta en el mercado. De esta 
manera, para amortiguar esa sobreabundancia de divisas, las autoridades monetarias van comprando y guardando en sus reservas internacionales dólares que no se usan para la importación.

Una cosa es el ingreso del capital y otra el uso efectivo que se traduce en el déficit en cuenta corriente, el cual empieza a crecer de modo significativo de US\$ 19 mil millones en 1991 a US\$ 55 mil millones en 1994 (si consideramos a 18 países de la región como se consignó en el Cuadro 1). En general, esto significa que pese a que las exportaciones han crecido, las importaciones lo han hecho a una mayor velocidad. En lo que va de la década, las exportaciones reales crecen en promedio $7 \%$ por año, mientras que las importaciones lo hacen en $15 \%$. De este modo, las economías se van äcostumbrando, cada vez a más, a un exceso de importaciones financiadas con los recursos de otros, lo que es sustentable sólo hasta cierto nivel. Es la repetición, en ese sentido, de lo ocurrido en los años setenta.

Los mercados se estaban acostumbrando a una situación insostenible, lo cual es sumamente peligroso. Si.nos endeudamos sabiendo que al año siguiente va a desaparecer el financiamiento, nos preparamos para ello. Pero América Latina ńo se preparó para eso sino, por el contrario, se preparó para seguir endeudándose. México tuvo un déficit en cuenta corriente de US\$29 mil millones en 1994 y sus proyecciones oficiales para 1995 eran de un aumento adicional del déficit de US\$ 4 mil millones, lo cual implica que no era una situación sustentable.

Sin embargo, hasta octubre de 1994, los mercados financieros privados seguian confiados colocando más recursos en América Latina, donde México y Argentina lideraban el proceso de abultados déficit en cuenta comiente ( $9 \%$ del PIB en México y $5 \%$ en Argentina).

\section{El caso de México.}

América Latina ha sido choqueada por la crisis que detonó en diciembre de 1994 en México. Ello golpeó el creciente optimismo que campeaba entonces en la región. Un optimismo con buenas razones, pero también con demasiado voluntarismo y cierta visión alejada de la realidad. Se había pasado del sobrepesimismo de los 80 al sobreoptimismo de los 90 . Siempre pesó en ello, en exceso, la dimensión financierista por sobre la de la economía real productiva. La gran afluencia de capitales extemos, muchos de corto plazo, registrada por un gran número de paises' de América Latina, impedían ver las debilidades de la economía real: poca 
inversión productiva, bajo ahorro, calidad de la educación deteriorada, muchos sectores de la población en extrema pobreza, ... y déficit extemo creciente en paises como México.

\section{a) Origenes de la crisis mexicana.}

El problema de México se generó muchos años antes de 1994. La recuperación de México postcrisis de la deuda de los años 80 tuvo lugar paulatinamente en la segunda mitad de ese decenio. Prosiguió en los 90 , pero con una recuperación sólo modesta de la inversión, no obstante que los ingresos de capitales externos crecian velozmente.

¿Cómo se usaron esos recursos del exterior? En financiar gastos del país, públicos o privados, en consumo o inversión, en exceso por sobre lo que se producia. Es lo que también se llama déficit del sector externo. En México, ese déficit se elevó de US\$7 mil millones en 1990 a US\$14 mil millones en 1991, siguió escalando en los años siguientes y llegó a US\$29 mil millones en 1994 (ver el Cuadro 1).

Lo que podía ser financiable por uno o dos años, no lo era por cinco o seis. Sin embargo, como se recordó más arriba, los financistas hasta fines de 1994 decían que no había problemas y que la economía mexicana era un muy buen destino para sus fondos. Esto permitió y estimuló a México a seguir acumulando pasivos externos en montos crecientes que llevarian a una crisis, tarde o temprano. Es el costo de una visión miope, que sólo miraba los méritos indudables de muchos logros de México, pero no los problemas que subsistían y los que se estaban creando.

En el camino, el tipo de cambio real se apreció fuertemente, desde 1988 y se acentuó en este decenio. Las exportaciones crecieron, pero las importaciones lo hicieron mucho más rápidamente. La inversión se recuperó, pero mucho menos que el ingreso de capitales. Por lo tanto, estos fondos extemos fueron a reforzar más intensamente el consumo y a desalentar el ahorro nacional. El aumento del consumo no fue gubernamental, pues México tenía una situación fiscal equilibrada. Entonces, el que gastó en exceso fue principalmente el sector privado, financiado por aportes privados del exterior. El ahorro interno mexicano cayó significativamente como porcentaje del PIB.

\section{b) Chile en 1982 .}

Es muy informativo recordar lo que pasó en Chile en 1982, año en que sufrió la peor crisis de toda Latinoamérica. Su PIB cayó 15\%. Chile tenia libre importación y un tipo de cambio fijo, congelado entre 1979 y 1982, 
y había optado por no hacer política monetaria; una cuenta de capitales muy abierta, y regulaciones muy permisivas de supervisión bancaria. Estas fueron las causas principales de la crisis de 1982.

Luego de haber acostumbrado a la economía chilena a volúmenes muy crecientes de financiamiento externo entre 1977 y 1981, éstos empezaron a moderarse a finales de 1981. La opción del gobierno fue decir que en una economía "sana y libre", no había que hacer nada, salvo reiterar la continuidad de políticas pasivas y neutras. Lo errado del enfoque fue evidente. En el primer semestre de 1982 el PIB ya se había reducido fuertemente, la producción industrial descendió 19\%, el desempleo abierto se elevó a $20 \%$ y la solvencia de la banca fue deteriorándose. Recién en junio de 1982, el gobierno reconoció en parte sus errores, entre otros devaluando masivamente el tipo de cambio. Dada la tardanza, obviamente fue un acontecimiento traumático, que se adicionó a la grave recesión que ya estaba en marcha desde hacía varios meses.

\section{Un camino alternativo.}

Así como la crisis mexicana de 1994 se fue generando por años, la fortaleza de Chile también se construyó en varios años. Evidentemente no es inmune, pero sí es mucho menos vulnerable. Esta mayor fortaleza se debe, fundamentalmente, a que, frente a la abundancia de fondos externos, Chile tuvo una política cauta y visionaria en los años recientes.

La experiencia de Chile ilustra las posibilidades de aplicar políticas activas en relación a los flujos de capitáles provenientes del exterior. En efecto, este país enfrenta una gran oferta de financiamiento externo desde los primeros días de la transición política, en 1990. Sin embargo, durante la crisis de la deuda de los años ochenta, fue el país más golpeado de la región, con la mayor reducción del PIB ( $15 \%$ en un año), y con una tasa de desempleo cercana al $30 \%$. Esto ocurrió porque se endeudó excesivamente, a la luz de una concepción neoliberal extrema, que creía que todos los mercados se ajustaban espontáneamente, comprobándose de manera dramática que los mercados pueden desequilibrarse y que el proceso de recuperación es muy duro.

En los años noventa, en vez de recibir todos los recursos que le ofrecian y gastarlos y dejar apreciarse más el peso, optó por restringir los ingresos de capitales de corto plazo. En 1991, se establecieron un impuesto y un fuerte encaje o reserva sin intereses, tanto sobre los créditos extemos como sobre los depósitos en moneda extranjera. Así, 
con esta y otras medidas de regulación, se desalentó efectivamente el ingreso de capitales especulativos.

Esta es la gran razón de por qué Chile tiene un déficit externo moderado, la deuda de corto plazo es moderada y manejable, la inversión interna es la más alta de la historia, y el tipo de cambio estaba en 1994 mejor situado que en la mayoría de los paises del continente (como se aprecia en el Cuadro 1). Sólo en la Bolsa se dejó erróneamente abierta una puerta para el uso de fondos externos en la compra de acciones en el mercado bursátil local (en operaciones llamadas de ADRs secundarios), que ha causado problemas localizados, y que después se ha atacado (desde julio de 1995 también quedaron afectos a encaje).

Las políticas que se aplican en la actualidad para desalentar los ingresos de capital financiero en Chile consisten en el equivalente a un impuesto al ingreso de capital. Esto es, el que trae 100 dólares al país, tiene que poner, adicionalmente, 30 dólares que se retienen durante un año en el Banco Central sin intereses. Esto implica que el que ingresa dinero tiene un costo asociado a la inmovilización de esos recursos, el cual es inversamente proporcional al plazo de su inversión. Al que invierte por un plazo de 10 años le cuesta proporcionalmente muy poco mantener esos recursos congelados por un año; al que invierte por semanas o meses, en cambio, le resulta muy costoso; además, se aplica un impuesto a los créditos externos, los bancos locales no pueden transferir al mercado interno créditos externos, la supervisión prudencial del sistema financiero es estricta y la inversión extranjera directa está sujeta a un plazo mínimo de permanencia de un año.

A esto se agrega una política cambiaria muy activa para intentar sostener el tipo de cambio y suavizar las apreciaciones cambiarias. En el Cuadro 1 se puede observar los tipos de cambio reales y constatar que Chile tuvo revaluaciones cambiarias mucho más pequeñas que México y Argentina.

En general, las apreciaciones cambiarias excesivas tienden a generar muchos desequilibrios y menor sustentabilidad. Esto aumenta la vulnerabilidad de las economías nacionales frente a shocks externos adversos. Cuando se tiene una economía que logra mayor estabilidad cambiaria real, y que las tasas de interés no se eleven en exceso, hay mayores posibilidades de crecimiento. En Chile, entre 1975 y 1984, hubo periodos con tasas de interés anual real de $30 \%$ o $40 \%$ y bajos coeficientes de inversión. Por ello, el crecimiento económico también resultó muy reducido; de hecho, la tasa promedio de crecimiento del PIB, entre 1974 y 1989, fue inferior al 3\%. En la actualidad, con tasas de interés entre $6 \%$ 


\section{R. Ffrench-Davis / Capitales golondrina, estabilidad ...}

y $9 \%$ y una macroeconomía que aparece como más sostenible, se realiza más inversión y, recién ahora, el crecimiento se ubica entre 6 y $7 \%$.

Lo que debe buscar la política macroeconómica es que la demanda agregada -esto es, la capacidad de gasto de la economía, que depende de la cantidad de dinero que se emita, de las normas de crédito, de las tasas de interés, etc.-, sea consistente con la capacidad productiva. Las políticas macroeconómicas neoliberales son profundamente simplistas y erráticas. Se caracteriza por topar techo y caerse, para volver a topar techo y volver a caer. El esquema alternativo propuesto, en cambio, tiene mucho más de la vertiente neoestructuralista, que reconoce las características concretas de nuestros mercados, considera cómo funcionan los mercados internacionales y comprende que nuestros mercados internos no se ajustan instantáneamente (más bien les cuesta mucho ajustarse), y que no debemos someterlos permanentemente a aceleradas y frenadas bruscas.

Esto tiene relación con la implementación de las políticas monetaria, tributaria, fiscal y de ingresos; y con la capacidad para concertar los intereses de empresarios, trabajadores y gobierno. Estos elementos han estado presentes en la experiencia chilena de retomo a la democracia y explican por qué Chile, en los últimos tres años, ha tenido una tasa de inversión notablemente alta, en comparación con los 20 años anteriores. También explica por qué el crecimiento del PIB es ahora sustentable, con una tasa de alrededor de $6 \%$ o $7 \%$ anual, superior a la tasa inferior al $3 \%$ que exhibia en las décadas de los setenta y ochenta.

Todo esto tiene mucho que ver, evidentemente, con el tratamiento a los movimientos de capitales. A este respecto, desgraciadamente, en América Latina han influido mucho los "ideologismos", es decir, la confianza excesiva en una apertura indiscriminada de los movimientos de capitales, la cual es tremendamente costosa desde el punto de vista productivo porque en las aceleradas y frenadas es donde se producen los grandes cambios distributivos.

Cuando uno tiene una economía estable, es muy dificil que se produzcan enormes vuelcos negativos en la distribución del ingreso. En cambio, en las economías que experimentan caídas del PIB de $15 \%$ como Chile en 1982, o de 7\% como en México en 1995, aumenta el desempleo muy fuertemente. En ese contexto, se produce mucha concentración del ingreso, la mayoría de la población se ve afectada y sólo un $5 \%$ o 10\%, los que pueden correr más rápido, se benefician al comprar baratas las empresas que tienen problemas financieros, pagar salarios más bajos porque hay mayor desempleo, captar tasas de interés elevadas, etc. 
Como en esos períodos se producen fuertes concentraciones del ingreso, para sembrar equidad se debe también manejar las políticas económicas de manera más sustentable, corrigiendo los precios "incorrectos". A menudo se requieren políticas más sofisticadas para lograr tasas de interés internas más razonables y tipos de cambio sustentables en el tiempo. Estos son los precios "correctos" para estimular el desarrollo y la generación de empleo productivo.

\section{Lecciones para América Latina.}

Primero, no se debe renunciar a poder hacer política cambiaria, amarrándose las manos con un tipo de cambio nominal fijo. Segundo, es preciso cautelar que el ingreso de fondos se dirija hacia la inversión productiva; las filtraciones excesivas hacia la inversión puramente bursátil y el consumo, conducen a burbujas y desequilibrios insostenibles. Tercero, la apertura indiscriminada de la cuenta de capitales puede ser muy perjudicial para el desarrollo productivo y para el bienestar de la mayoría de la gente. Una regulación eficaz y eficiente es posible, y Chile to ha demostrado desde 1991. Adecuadas políticas cambiarias y monetarias son esenciales, un paso necesario, aunque obviamente insuficiente, para generar un desarrollo económico y social sostenible. 